\title{
DEPOSIÇÃO DE SERAPILHEIRA EM POVOAMENTO DE PINUS ${ }^{1}$
}

\author{
Gabriel Piovesan ${ }^{2}$, Mauro Valdir Schumacher ${ }^{2}$, \\ Márcio Viera ${ }^{3}$, Vicente Guilherme Lopes ${ }^{2}$, Carline Welter ${ }^{2}$
}

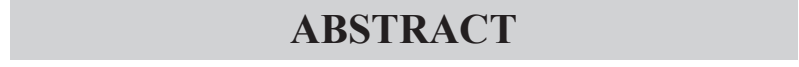

\section{LITTERFALL DEPOSITION IN A PINUS STAND}

Litterfall is the main responsible for maintaining forest stands yield in soils with low natural fertility. This study aimed to evaluate seasonal and monthly litterfall deposition in a Pinus taeda L. stand, in Quedas do Iguaçu, Paraná State, Brazil. Three plots with $21.0 \mathrm{~m}$ x $20.0 \mathrm{~m}$ were randomly allocated, where four collectors of $1.0 \mathrm{~m}^{2}$ each were systematically distributed. The litterfall was monthly collected, between April 2007 and March 2009, respectively at eight and nine years after the stand plantation, and divided in needles, thin branches (diameter $<0.5 \mathrm{~cm}$ ), and miscellaneous, being subsequently determined its dry mass. The litterfall annual deposition reached 7.1 $\mathrm{Mg} \mathrm{ha}^{-1}$, being higher in the autumn. The average maximum temperature and average air temperature had inverse and significant influence on needles deposition and total litterfall.

KEY-WORDS: Pinus taeda L.; senescent material; seasonality; reforestation.

\section{INTRODUÇÃO}

A crescente preocupação com a preservação do meio ambiente, as restrições legais e os impedimentos burocráticos tornam o uso madeirável de florestas nativas bastante restrito. A partir deste impedimento, o setor industrial madeireiro, especialmente da Região Sul do Brasil, que apresenta cerca de $83 \%$ dos 1.641.892 ha de pinus plantados no País (Abraf 2012), adequou-se à nova realidade, com o uso de madeira de plantios florestais, destacando-se o gênero Pinus, sendo o Pinus taeda e o Pinus elliottii, originários do sul dos Estados Unidos, as espécies mais utilizadas (IAP 2007). Estas espécies destacam-se como matéria-prima em atividades industriais, as

\section{RESUMO}

A serapilheira é a principal responsável pela manutenção da produtividade de povoamentos florestais estabelecidos em solos com baixa fertilidade natural. Objetivou-se, com este trabalho, avaliar a deposição mensal e estacional de serapilheira em um povoamento de Pinus taeda L., no município de Quedas do Iguaçu (PR). Instalaram-se, ao acaso, três parcelas de 21,0 m x 20,0 m, nas quais distribuíram-se, sistematicamente, quatro coletores de $1,0 \mathrm{~m}^{2}$ cada. As coletas foram realizadas mensalmente, entre abril de 2007 e março de 2009, respectivamente aos oito e nove anos de idade do povoamento. A serapilheira foi separada nas frações acículas, galhos finos (diâmetro $<0,5 \mathrm{~cm}$ ) e miscelânea, sendo, posteriormente, determinada a massa seca. A deposição anual de serapilheira foi de $7,1 \mathrm{Mg} \mathrm{ha}^{-1}$, com deposição superior no outono. A temperatura máxima média e a temperatura média do ar apresentaram influência inversa e significativa na deposição de acículas e na serapilheira total.

PALAVRAS-CHAVE: Pinus taeda L.; material senescente; sazonalidade; reflorestamento.

quais constituem bases importantes para a economia no Sul do Brasil, para a produção de papel, celulose, compensados, aglomerados, embalagens, mobiliário e chapas, dentre outros (Ferreira et al. 2004).

Muitas vezes, a implantação de povoamentos florestais ocorre em solos com baixa fertilidade natural, pois os mais férteis são destinados ao cultivo de espécies agrícolas. Estes povoamentos, principalmente de pinus, raramente recebem adição de nutrientes via adubação, ou, quando esta é realizada, na maioria das vezes, ocorre apenas na cova (Melo \& Resck 2002). Segundo os mesmos autores, o volume de nutrientes adicionado, neste tipo de adubação, é pequeno, e isto faz com que os nutrientes exigidos durante o crescimento da planta sejam supridos pela

1. Trabalho recebido em jul./2011 e aceito para publicação em jun./2012 (nº registro: PAT 15131).

2. Universidade Federal de Santa Maria, Departamento de Ciências Florestais, Santa Maria, RS, Brasil.

E-mails: gabriel_piovesan@yahoo.com.br, mvcschumacher@gmail.com, viguelopes@yahoo.com.br, carlinewelter@hotmail.com.

3. Fundação Estadual de Pesquisa Agropecuária, Centro de Pesquisa em Florestas, Santa Maria, RS, Brasil.

E-mail: marcio-viera@fepagro.rs.gov.br. 
reserva do solo e pelos resíduos orgânicos acumulados sobre o piso florestal.

A serapilheira é a principal formadora do material orgânico do solo, sendo constituída por fragmentos orgânicos, provenientes da parte aérea da planta, tais como galhos, folhas, cascas, frutos, caules e flores, bem como restos animais e material fecal. A serapilheira, além de participar na ciclagem de nutrientes, é eficiente na proteção contra a erosão, devido à espessa camada formada, evitando o impacto direto da água da chuva no solo (Corrêa Neto et al. 2001).

Desta forma, a presença da serapilheira é de fundamental importância para a estabilidade e produtividade de povoamentos de pinus. Esta importância é evidenciada quando verifica-se que muitos povoamentos mantêm-se em áreas com solos de baixa fertilidade e incapazes de suportar outras culturas (Viera \& Schumacher 2010). Devido a estas características, é fundamental estudar o comportamento da serapilheira depositada, a fim de se obter informações que possibilitem um melhor entendimento da dinâmica existente em plantações florestais, visto que o comportamento da deposição de serapilheira é dinâmico, variando estacionalmente e sendo influenciado pela temperatura ou pluviosidade, bem como pela idade das árvores.

Assim, objetivou-se, neste estudo, avaliar a deposição mensal e estacional de serapilheira em um povoamento de Pinus taeda L. de oito anos de idade e sua relação com a temperatura do ar e a pluviosidade.

\section{MATERIAL E MÉTODOS}

O estudo foi realizado em um povoamento de Pinus taeda L. de oito anos de idade, localizado no município de Quedas do Iguaçu, PR (2527'22”S, $52^{\circ} 54^{\prime} 39^{\prime \prime} \mathrm{W}$ e altitude média de $630 \mathrm{~m}$ ).

O clima, segundo Köppen, é classificado como $\mathrm{Cfa}$, subtropical úmido, com verão quente e temperatura média anual de $20^{\circ} \mathrm{C}$. A precipitação média anual é de $1.780 \mathrm{~mm}$ e a do mês mais seco é de $60,0 \mathrm{~mm}$ (Embrapa 1984). Na Tabela 1, são apresentados os valores de temperatura e precipitação registrados durante os dois anos de estudo, na Estação Meteorológica de Quedas do Iguaçu (PR), próxima à área de pesquisa.

O relevo onde o povoamento foi implantado é suave-ondulado, apresentando solo classificado como Latossolo Vermelho distroférrico, caracterizado por ser um solo profundo, avermelhado, com presença de óxidos e textura argilosa (Embrapa 1999).

O povoamento de Pinus taeda L. utilizado no estudo foi implantado em junho de 1999, em espaçamento de $3,0 \mathrm{~m} \times 2,0 \mathrm{~m}$ e sem adubação de plantio. No inventário realizado em agosto de 2008, o povoamento encontrava-se com 1.257 árvores ha-1, diâmetro médio à altura do peito de $18,3 \mathrm{~cm}$, altura média de $11,8 \mathrm{~m}$ e incremento médio anual (IMA) de 23,5 $\mathrm{m}^{3} \mathrm{ha}^{-1}$ ano $^{-1}$.

Para analisar a deposição de serapilheira no povoamento de Pinus taeda L., foram instaladas, ao acaso, três parcelas de $21,0 \mathrm{~m}$ x 20,0 m. Conforme metodologia descrita por Schumacher et al. (2004), em cada uma das parcelas, foram distribuídos, sistematicamente, quatro coletores de serapilheira, alocados em quatro posições distintas: um na linha de plantio, entre duas árvores; um na entrelinha de plantio, entre duas árvores; um na diagonal, entre quatro árvores; e o último encostado ao tronco da árvore, totalizando 12 coletores. Os coletores são do tipo bandeja, cada um com 1,0 $\mathrm{m}^{2}$ de área de coleta,

Tabela 1. Variação mensal da temperatura mínima média, temperatura média e temperatura máxima média do ar e da precipitação (Quedas do Iguaçu, PR).

\begin{tabular}{|c|c|c|c|c|c|c|c|c|c|c|c|c|c|}
\hline \multirow{2}{*}{ Variáveis } & \multirow{2}{*}{ Ano } & \multicolumn{12}{|c|}{ Mês } \\
\hline & & abr & mai & jun & jul & ago & set & out & nov & dez & jan & fev & mar \\
\hline \multirow{2}{*}{$\begin{array}{l}\text { Temperatura } \\
\text { mínima média }\left({ }^{\circ} \mathrm{C}\right)\end{array}$} & $2007 / 2008$ & 17,6 & 11,7 & 12,0 & 9,8 & 12,4 & 15,9 & 17,6 & 16,7 & 19,1 & 19,5 & 19,5 & 18,9 \\
\hline & $2008 / 2009$ & 18,8 & 16,3 & 15,0 & 14,5 & 16,3 & 16,9 & 18,8 & 19,5 & 19,6 & 19,7 & 19,8 & 20,0 \\
\hline \multirow{2}{*}{$\begin{array}{l}\text { Temperatura } \\
\text { média }\left({ }^{\circ} \mathrm{C}\right)\end{array}$} & $2007 / 2008$ & 23,4 & 17,2 & 18,0 & 15,9 & 19,0 & 23,1 & 23,3 & 22,7 & 25,3 & 24,6 & 24,9 & 24,5 \\
\hline & $2008 / 2009$ & 23,9 & 21,0 & 20,1 & 21,5 & 22,9 & 23,9 & 24,3 & 24,7 & 25,1 & 24,9 & 25,1 & 24,4 \\
\hline \multirow{2}{*}{$\begin{array}{l}\text { Temperatura } \\
\text { máxima média }\left({ }^{\circ} \mathrm{C}\right)\end{array}$} & $2007 / 2008$ & 29,1 & 22,7 & 24,0 & 21,9 & 25,5 & 30,3 & 29,0 & 28,6 & 31,5 & 29,7 & 30,2 & 30,0 \\
\hline & $2008 / 2009$ & 28,9 & 25,7 & 25,7 & 25,2 & 28,4 & 29,3 & 30,8 & 29,8 & 29,9 & 30,5 & 30,0 & 30,3 \\
\hline \multirow{2}{*}{ Precipitação (mm) } & $2007 / 2008$ & 209,0 & 234,0 & 22,0 & 72,0 & 10,0 & 16,0 & 99,0 & 152,0 & 301,0 & 77,0 & 162,0 & 16,0 \\
\hline & $2008 / 2009$ & 130,0 & 102,0 & 243,0 & 110,0 & 248,0 & 195,0 & 289,0 & 163,0 & 69,0 & 218,0 & 161,0 & 68,0 \\
\hline
\end{tabular}


disposta a $0,70 \mathrm{~m}$ de altura, em relação à superfície do solo, e composta de uma moldura de madeira, com fundo em tela de nylon de 1,0 mm.

Mensalmente, coletou-se o material interceptado pelos coletores, durante um período de dois anos (abril de 2007 a março de 2009). O material recolhido foi acondicionado em embalagem plástica, devidamente identificado e enviado ao Laboratório de Ecologia Florestal pertencente ao Departamento de Ciências Florestais da Universidade Federal de Santa Maria (RS). No laboratório, a serapilheira foi separada nos compartimentos acículas, galhos finos (diâmetro $<0,5 \mathrm{~cm}$ ) e miscelânea (casca e cones). Após esta separação, as amostras foram secas em estufa de circulação e renovação de $\mathrm{ar}$, a $70^{\circ} \mathrm{C}$, por um período de 72 horas, sendo, posteriormente, pesadas em balança digital de precisão $(0,01 \mathrm{~g})$.

Com base nos dados provenientes de cada coleta mensal de serapilheira (material armazenado sobre os coletores), foi estimada a quantidade média de deposição de serapilheira no piso florestal, durante o período de estudo.

Realizou-se análise de variância e o teste de comparação de médias de Tukey, para cada fração da serapilheira, em relação às estações de cada ano de avaliação. Tanto para o teste de comparação de médias, como para a análise de correlação de Pearson (r), entre a deposição de serapilheira e as variáveis climáticas, a 5\%, utilizou-se o software SPSS (IBM 1996).

\section{RESULTADOS E DISCUSSÃO}

A deposição média anual de serapilheira foi de 7,1 $\mathrm{Mg} \mathrm{ha}^{-1}$, sendo, esta, formada por acículas $(95,6 \%)$, galhos finos $(2,3 \%)$ e miscelânea $(2,1 \%)$ (Tabela 2). Esta deposição situa-se próxima aos valores encontrados por outros autores, para o Pinus taeda L. Poggiani et al. (1987) verificaram deposição média anual de 4,4 $\mathrm{Mg} \mathrm{ha}^{-1}$, em um povoamento de Pinus taeda L. com sete e oito anos de idade, plantado em área degradada pela extração de xisto betuminoso, no Paraná. Koehler (1989), analisando sítios com produtividades diferentes, encontrou deposição média anual variando de $6,5 \mathrm{Mg} \mathrm{ha}^{-1}$ a $8,7 \mathrm{Mg} \mathrm{ha}^{-1}$, em plantios de Pinus taeda L. com 15 anos de idade, na região de Ponta Grossa (PR). Schumacher et al. (2008) observaram deposição de $4,5 \mathrm{Mg} \mathrm{ha}^{-1} \mathrm{e}$ Viera \& Schumacher (2010) de 2,5 $\mathrm{Mg} \mathrm{ha}^{-1}$, em povoamentos de Pinus taeda L. com cinco a sete anos
Tabela 2. Deposição média mensal de serapilheira $\left(\mathrm{kg} \mathrm{ha}^{-1}\right) \mathrm{em}$ um povoamento de Pinus taeda L. (Quedas do Iguaçu, PR, 2007/2009).

\begin{tabular}{ccrrr}
\hline Mês & \multicolumn{1}{c}{ Acículas } & \multicolumn{1}{c}{ Galhos } & Miscelânea & \multicolumn{1}{c}{ Total } \\
\hline Abr & $1.013,1(98,6)^{*}$ & $7,3(0,7)$ & $7,2(0,7)$ & $1.027,5$ \\
Mai & $794,7(97,0)$ & $2,0(0,2)$ & $23,0(2,8)$ & 819,7 \\
Jun & $1.192,1(98,4)$ & $8,6(0,7)$ & $11,3(0,9)$ & $1.212,0$ \\
Jul & $539,9(97,0)$ & $11,1(2,0)$ & $5,7(1,0)$ & 556,7 \\
Ago & $566,7(93,2)$ & $22,9(3,8)$ & $18,5(3,0)$ & 608,1 \\
Set & $219,7(83,9)$ & $26,0(9,9)$ & $16,2(6,2)$ & 261,9 \\
Out & $375,4(87,1)$ & $35,7(8,3)$ & $20,1(4,7)$ & 431,1 \\
Nov & $321,8(94,1)$ & $7,5(2,2)$ & $12,8(3,7)$ & 342,0 \\
Dez & $299,2(93,6)$ & $8,5(2,6)$ & $12,0(3,8)$ & 319,7 \\
Jan & $454,9(97,1)$ & $7,2(1,5)$ & $6,3(1,3)$ & 468,4 \\
Fev & $601,2(95,7)$ & $19,3(3,1)$ & $8,1(1,3)$ & 628,5 \\
Mar & $378,7(97,0)$ & $5,7(1,5)$ & $6,2(1,6)$ & 390,6 \\
\hline Total & $6.757,2(95,6)$ & $161,8(2,3)$ & $147,2(2,1)$ & $7.066,2$ \\
\hline
\end{tabular}

* Valores entre parênteses referem-se ao percentual de cada fração, em relação ao total de serapilheira, para um determinado mês.

de idade, em área de segunda e primeira rotação, respectivamente, no Rio Grande do Sul.

A quantidade de serapilheira produzida foi similar à de outras espécies do gênero Pinus, como verificado por Poggiani (1985), para Pinus oocarpa $\left(7,1 \mathrm{Mg} \mathrm{ha}^{-1}\right)$ e Pinus caribaea var. hondunensis $\left(8,4 \mathrm{Mg} \mathrm{ha}^{-1}\right)$, aos 11 anos de idade.

No estudo de Melo \& Resck (2002), para três diferentes procedências de Pinus caribaea, aos 16 anos de idade, a quantidade de quedas de acículas, em relação ao total depositado, foi, em média, de 92,7\%. A percentagem superior da fração acículas encontrada neste estudo, em Quedas do Iguaçu (PR), decorre da maior juvenilidade do povoamento, o qual ainda não apresenta elevada taxa de frutificação, a qual poderia aumentar a percentagem da fração miscelânea.

A deposição da fração acículas foi mais acentuada em junho do ano 1 e abril do ano 2, e os galhos tiveram picos de deposição por volta dos meses de setembro e outubro e a miscelânea em maio, para o ano 1 (Figura 1). De forma geral, os meses que mais colaboraram na deposição mensal foram abril, maio e junho, com, aproximadamente, $43,3 \%$ do total. A deposição apresentou-se sazonal, sendo superior $(\mathrm{p}<0,05)$ no outono, seguido pelo verão, inverno e primavera (Figura 2). Para galhos e miscelânea, ocorreu variação na quantidade de galhos, no inverno do ano 2, possivelmente pela grande diferença de precipitação, em relação ao inverno do ano 1 (Tabela 1). Nas demais frações, não ocorreram variações significativas. 

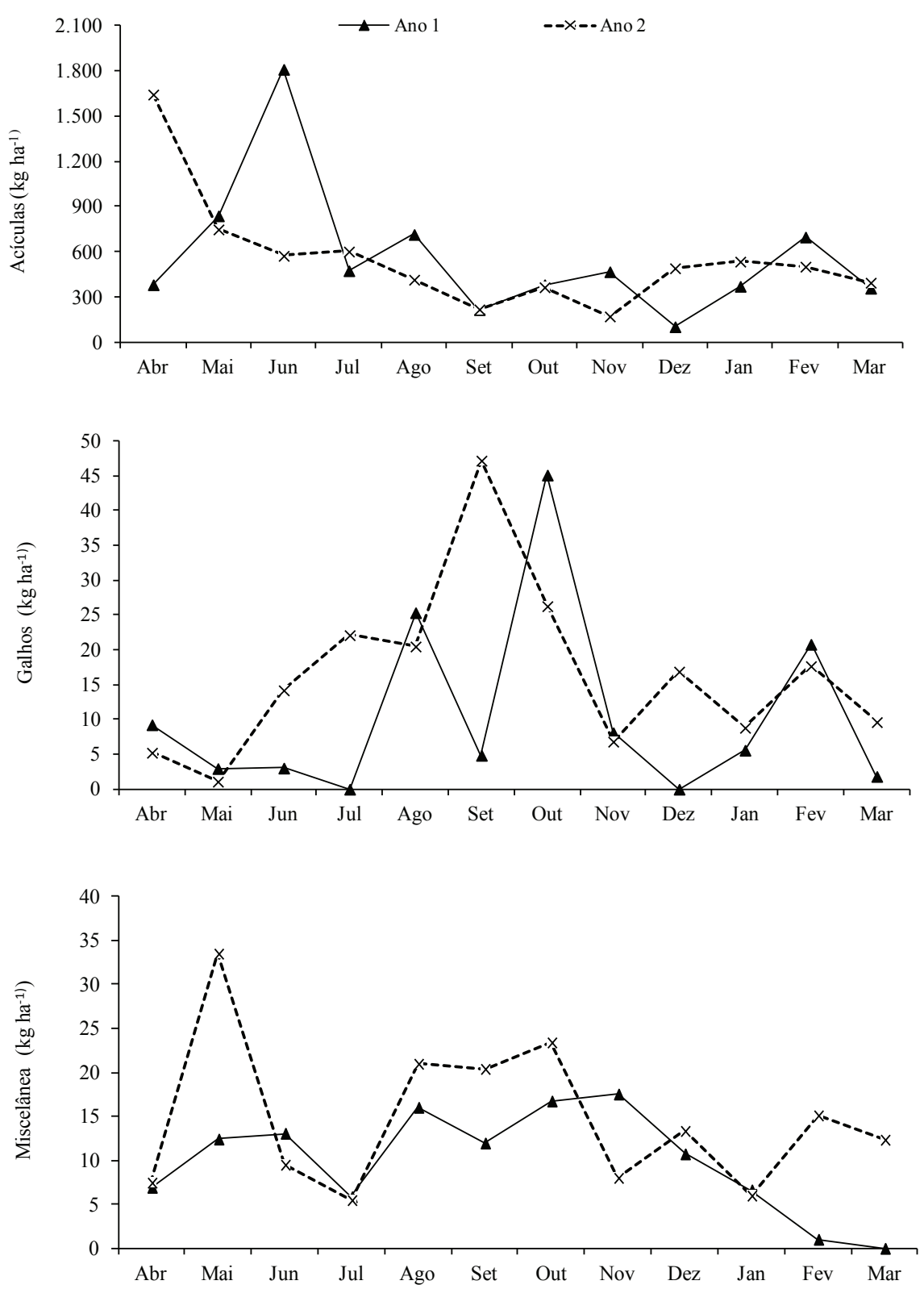

Figura 1. Deposição média mensal de acículas, galhos e miscelânea (kg ha $\left.{ }^{-1}\right)$, no ano 1 (abril/2007 a março/2008) e ano 2 (abril/2008 a março/2009) (Quedas do Iguaçu, PR).

Segundo Brum et al. (2001), a sazonalidade de deposição varia de espécie para espécie, dependendo da região em que se encontram, pois, em regiões temperadas e frias, a chegada do outono é sempre o período que desencadeia o processo de derrubada total de folhas.

Para Schumacher et al. (2008), em estudo com Pinus taeda L., em Cambará do Sul (RS), o povoamento apresentou magnitude sazonal média de deposição seguindo a ordem estacional inverno = outono $>$ verão $>$ primavera, sendo esta variável em cada ano de observação e não estando bem definida, em razão da juvenilidade das plantas.

Em um povoamento de Pinus taeda L. estudado por Koehler (1989), na região de Ponta Grossa (PR), foi verificada maior produção de serapilheira no outono e menor no período inverno-primavera, com correlação positiva e significativa entre a produção de serapilheira e a umidade relativa do ar.

Poggiani et al. (1987), em estudo realizado no Paraná, em talhões de Pinus taeda L., Eucalyptus viminalis e Mimosa scabrella, para recuperação de 

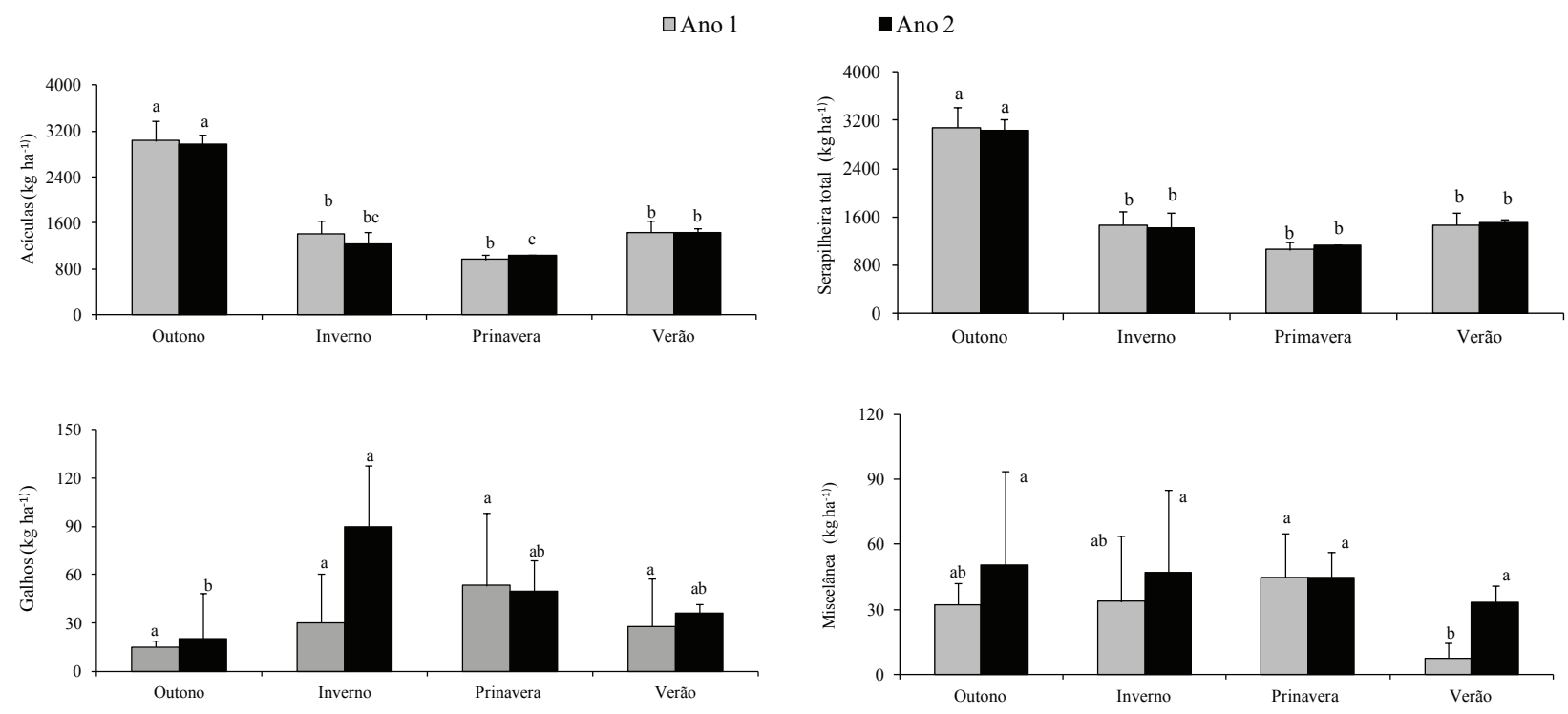

Figura 2. Deposição estacional das frações de serapilheira no ano 1 (abril/2007 a março/2008) e ano 2 (abril/2008 a março/2009) (Quedas do Iguaçu, PR). Frações de serapilheira seguidas por mesma letra, nas diferentes estações do ano, não diferem entre si, pelo teste Tukey, a 5\%. Barras na vertical indicam o desvio-padrão.

área degradada pela mineração de xisto, encontraram, para Pinus taeda L., uma acentuada produção de folhedo, no período de abril a junho. No local de ocorrência natural da espécie Pinus taeda L., na Carolina do Norte (EUA), Wells et al. (1972) constataram que a espécie deposita mais acentuadamente suas acículas durante o outono e no início do inverno, sendo o mesmo verificado em plantios fora de sua área de ocorrência natural.

Com relação às variáveis climáticas do povoamento, a temperatura máxima média e a temperatura média do ar apresentaram influência inversamente proporcional na deposição de acículas e serapilheira total (Tabela 3). As variáveis climáticas não influenciaram significativamente na deposição dos compartimentos galhos e miscelânea.

Tabela 3. Correlação de Pearson (r) entre a deposição de serapilheira e as variáveis climáticas, de abril de 2007 a março de 2009 (Quedas do Iguaçu, PR).

\begin{tabular}{|c|c|c|c|c|}
\hline Serapilheira & $\begin{array}{c}\text { Temp. } \\
\text { máx. média }\end{array}$ & $\begin{array}{l}\text { Temp. } \\
\text { mín. média }\end{array}$ & $\begin{array}{l}\text { Temp. } \\
\text { média }\end{array}$ & Precip. \\
\hline $\mathrm{kg} \mathrm{ha}^{-1}$ & 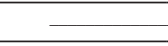 & $-{ }^{\circ} \mathrm{C}$ & $\bar{z}$ & $\mathrm{~mm}$ \\
\hline Acículas & $-0,46^{*}$ & $-0,34$ & $-0,40^{*}$ & $-0,25$ \\
\hline Galhos & 0,18 & 0,10 & 0,14 & 0,13 \\
\hline Miscelânea & $-0,07$ & $-0,10$ & $-0,09$ & 0,16 \\
\hline Serapilheira total & $-0,46^{*}$ & $-0,35$ & $-0,40^{*}$ & $-0,25$ \\
\hline
\end{tabular}

Estudando a correlação de Pearson entre as variáveis climáticas e a produção mensal de serapilheira, Cianciaruso et al. (2006), em trabalho sobre a produção de serapilheira e decomposição do material foliar em um Cerradão, no município de Luiz Antônio (SP), encontraram correlação negativa entre a umidade do ar e a temperatura média. Já para König et al. (2002), na avaliação da sazonalidade da produção de serapilheira, em floresta estacional decidual, no município de Santa Maria (RS), observaram que a produção de serapilheira esteve correlacionada com a temperatura média mensal, comportando-se de forma inversa $(r=-0,54)$, não obtendo-se correlação para a variável precipitação, sendo esta correlação negativa $(r=-0,66)$ também encontrada por Schumacher et al. (2008), no segundo ano de estudo.

\section{CONCLUSÃO}

A deposição de serapilheira foi estacional, demonstrando que povoamentos de Pinus taeda L. possuem maior produção de material senescente durante o período do outono, com a chegada de baixas temperaturas, não estando relacionada com a precipitação pluviométrica. $\mathrm{O}$ material produzido é essencialmente composto por acículas, devido à juvenilidade das árvores. 


\section{AGRADECIMENTOS}

Ao Conselho Nacional de Desenvolvimento Científico e Tecnológico $(\mathrm{CNPq})$, pela bolsa de iniciação científica concedida ao primeiro autor, e à empresa Araupel S/A, pela manutenção da área experimental, coleta, envio de amostras e auxílio logístico.

\section{REFERÊNCIAS}

ASSOCIAÇÃO BRASILEIRA DE PRODUTORES DE FLORESTAS PLANTADAS (Abraf). Anuário estatístico da ABRAF 2012, ano base 2011. Brasília, DF: Abraf, 2012.

BRUM, E. J. et al. Relação entre a produção de serapilheira e variáveis meteorológicas em três fases sucessionais de uma floresta estacional no Rio Grande do Sul. Revista Brasileira de Agroclimatologia, Santa Maria, v. 9, n. 2, p. 277-285, 2001.

CIANCIARUSO, M. V. et al. Produção de serapilheira e decomposição do material foliar em um Cerradão na Estação Ecológica do Jataí, no município de Luiz Antônio, SP, Brasil. Acta Botanica Brasilica, São Paulo, v. 20, n. 1, p. 49-59, 2006.

CORREAA NETO, T. A. C. et al. Deposição de serapilheira e mesofauna edáfica em áreas de eucalipto e floresta secundária. Floresta e Ambiente, Rio de Janeiro, v. 8, n. 1, p. 70-75, 2001.

EMPRESA BRASILEIRA DE PESQUISA AGROPECUÁRIA (Embrapa). Serviço Nacional de Levantamento e Conservação de Solos. Levantamento de reconhecimento dos solos do Estado do Paraná. Curitiba: Embrapa, 1984.

EMPRESA BRASILEIRA DE PESQUISA AGROPECUÁRIA (Embrapa). Sistema brasileiro de classificação de solos. Rio de Janeiro: Embrapa, 1999.

FERREIRA, C. A. et al. Pesquisa sobre nutrição de pinus no Sul do Brasil. Revista da Madeira, Curitiba, n. 83, 2004. Disponível em: <http://www.remade.com.br/br/ revistadamadeira_materia.php?num $=600 \&$ subject $=$ Nutri $\% \mathrm{C} 3 \% \mathrm{~A} 7 \% \mathrm{C} 3 \% \mathrm{~A} 30 \&$ title=Pesquisas $>$. Acesso em: 16 out. 2010.

IBM. Statistical package for the social sciences - SPSS. Versão 7.5.1. Chicago: IBM, 1996.

INSTITUTO AMBIENTAL DO PARANÁ (IAP). Biodiversidade e áreas protegidas. 2007. Disponível em: $<$ http://www.pr.gov.br/meioambiente/iap $>$. Acesso em: 22 set. 2009.
KOEHLER, W. C. Variação estacional de deposição de serapilheira e de nutrientes em povoamentos de Pinus taeda na região de Ponta Grossa - PR. 1989. 138 f. Tese (Doutorado em Ciências Florestais)-Universidade Federal do Paraná, Curitiba, 1989.

KÖNIG, F. G. et al. Avaliação da sazonalidade da produção de serapilheira numa floresta estacional decidual no município de Santa Maria - RS. Revista Árvore, Viçosa, v. 26, n. 4, p. 429-435, 2002.

MELO, J. T.; RESCK, D. V. S. Retorno, ao solo, de nutrientes de serapilheira de pinus no Cerrado do Distrito Federal. Planaltina: Embrapa Cerrados, 2002. (Boletim de pesquisa e desenvolvimento, 75).

POGGIANI, F. Ciclagem de nutrientes em ecossistemas de plantações florestais de Eucalyptus e Pinus: implicações silviculturais. 1985. 229 f. Tese (Livre docência)-Escola Superior de Agricultura Luiz de Queiroz, Universidade de São Paulo, 1985.

POGGIANI, F. et al. Quantificação da deposição de folhedo em talhões experimentais de Pinus taeda, Eucalyptus viminalis e Mimosa scabrella plantados em uma área degradada pela mineração do xisto betuminoso. $I P E F$, Piracicaba, v. 47, n. 1, p. 21-29, 1987.

SCHUMACHER, M. V. et al. Produção de serapilheira em uma floresta de Araucaria angunstifolia (Bertol.) Kuntze no município de Pinhal Grande - RS. Revista Árvore, Viçosa, v. 28, n. 1, p. 29-37, 2004.

SCHUMACHER, M. V.; VIERA, M.; WITSCHORECK, R. Produção de serapilheira e transferência de nutrientes em área de segunda rotação com floresta de Pinus taeda no município de Cambará do Sul, RS. Ciência Florestal, Santa Maria, v. 18, n. 4, p. 471-480, 2008.

SIMEPAR: sistema meteorológico do Paraná. 2009. Disponível em: $<$ http://www.agritempo.gov.br/agroclima/ sumario?uf=PR $>$. Acesso em: 21 set. 2009.

VIERA, M.; SCHUMACHER, M. V. Variação mensal da deposição de serapilheira em povoamento de Pinus taeda L. em área de campo nativo em Cambará do Sul RS. Revista Árvore, Viçosa, v. 34, n. 3, p. 487-494, 2010.

WELLS, C. G. et al. Investigation of mineral nutrient cycling in an upland Piemont forest. Journal of the Elisha Mitchell Scientific Society, Chapel Hill, v. 88, n. 2, p. 6678, 1972. 